\title{
Effect of Formulation and Process Variables on the Material and Release Properties of Metronidazole Tablets Using Enterolobium Gum as Binder
}

\author{
John Oluwasogo AYORINDE ${ }^{*}{ }^{*}$, Michael Ayodele ODENIYI ${ }^{1}$
}

1Department of Pharmaceutics and Industrial Pharmacy, University of Ibadan, Ibadan, Nigeria.

\begin{abstract}
Using the $2^{3}(=8)$ factorial design to determine the effects of excipient modification and process techniques, on mechanical and release properties of tablets containing Enterolobium cyclocarpum gum.

Properties of the native (NG), physically modified (PMG) and chemically modified (CMG) gums were evaluated. Metronidazole tablets were prepared from formulations containing NG, PMG, CMG or HPMC. Individual and interacting effects of the parameters were evaluated using the factorial design.

Formulations showed drug release of $81-99 \%$. Nature and concentration of polymer, and processing technique $\left(\mathrm{X}_{1} \mathrm{X}_{2}\right.$ and $\mathrm{X}_{3}$ respectively) had the highest effect on disintegration time. Interaction between $\mathrm{X}_{1}$ and $\mathrm{X}_{3}$ had the greatest effect on the mechanical properties; interaction between $\mathrm{X}_{1}$ and $\mathrm{X}_{2}$ had the greatest effect on drug release.

Enterolobium gum produced tablets with high drug release which was sustained for 12 hours. Gum modification and other formulation variables need to be selected to achieve desired formulation objectives.
\end{abstract}

Keywords: Enterolobium gum, tablet properties, processing techniques, drug release 


\section{INTRODUCTION}

The three major methods employed in the production of tablets are direct compression, dry granulation and wet granulation. Each of these methods have different requirement in term of materials, concentration of the materials and procedure. The mechanical and release properties of tablets could be affected by these varying parameters.

Polymeric materials such as gums and starches have been widely used as binders in tablet formulations; however, locally sourced natural materials have advantages over the synthetic polymers ${ }^{1}$. Binders are employed in pharmaceutical tablet formulation to promote the bonding between the different components of a powder mix in a formulation thereby enhancing the strength of the eventual tablet produced. They are usually selected on basis of previous experience, particular product needs, literature or vendor data or the preference of the individual or manufacturing unit ${ }^{2}$. Binders are added either dry (in direct compression) or wet (in wet granulation) to form cohesive compact or granules.

According to Samia et al., (2009)3), exudate gums are formed as a result of microbial infection on the plants and the plants in turn synthesize the liquid substances as a defence mechanism to seal off the wound and prevent further invasion of the tissue. Natural gums are known for their physical properties and employed as excipients in pharmaceutical preparations where they are used as thickeners, emulsifiers, viscosity enhancers, drug release modifiers and binders. Gums are known to have binding properties; they impart cohesiveness in to the powder mass and convert them to granules ${ }^{4}$. Due to excellent properties of exudate gum such as solubility, viscosity, binding, stabilizing, thickening and emulsifying, they are used in adhesive industries, beverages, confectionaries, cosmetics, paint, paper, pharmaceutical and food industries ${ }^{5}$.

The physicochemical properties of gums in their native forms have been improved through various forms of modification. Agar and guar gums were modified by heat treatment at various temperatures in a hot air oven along with co-grinding of both materials. The modified gum was used as disintegrating agent $^{6}$. Ayorinde and Odeniyi (2014) ${ }^{7}$ investigated the effect of modification by microwave irradiation on the disintegrant properties of a starch and a gum in metronidazole tablet formulations.

Modification of gums can be done through derivatization of functional groups, grafting with polymers, cross-linking with ions etc. The techniques for modification of gums have been broadly classified into four categories namely: ${ }^{8}$ Physical, chemical, enzymatic, and genetic modifications. These modifications aim at 
producing various new derivatives with improved physicochemical properties along with useful structural attributes ${ }^{9,10}$.

The plant, Enterolobium cyclocarpum is one of the largest trees in the dry forest formation reaching up to $40 \mathrm{~m}$ in height and $3 \mathrm{~m}$ in diameter, with a huge spreading crown. It is commonly known as Guanacaste, Mexican walnut, Carocaro or Elephant-ear tree. It is species of flowering tree in the pea family, Fabaceae (Mimosoideae) that is native to tropical regions of America from central Mexico south to northern Brazil and Venezuela. In North America, it is often called elephant-ear tree due to the shape of the seedpods. It is evergreen or briefly deciduous for 1-2 months during the dry season. They have very fragrant flowers and their fruits are large, glossy dark brown indehiscent and spirallyorganized pods shaped like orbicular disks.

Enterolobium gum is usually a transparent dark brown gum, partially soluble in water. The gum also called Mexican walnut gum is obtained from incised trunk of Enterolobium cyclocarpum tree. The gum has been found to have potentials for use as a film forming polymer ${ }^{11}$.

This present study is therefore aimed at evaluating the native and modified Enterolobium gums as binders in metronidazole tablet formulations. The individual and interaction effects of various formulation parameters on mechanical and release properties of the tablets will also be investigated.

\section{METHODOLOGY}

\section{Materials}

The materials used in this study are Enterolobium cyclocarpum gum (obtained from Botanical garden, University of Ibadan, Nigeria), Metronidazole (Vision pharmaceutical Co Ltd, China), Hydroxylpropylmethyl cellulose (HPMC). All other reagents used were of Analar grade.

\section{Methods}

\section{Collection, Extraction and Characterization of Enterolobium Gum}

The collection and extraction process of Enterolobium gum have been reported in our previous studies ${ }^{12,1}$.

\section{Modification of Enterolobium Gum}

Modification was carried out using physical and chemical modification. In physical modification, a $70 \% \mathrm{w} / \mathrm{v}$ of the gum was prepared at $70{ }^{\circ} \mathrm{C}$, thoroughly mixed with $20.5 \mathrm{~g}$ ethylene glycol and then allowed to cool at room temperature. The obtained slurry was dried at $60{ }^{\circ} \mathrm{C}$ in an oven (Model DHG-9053A, 
Ocean Medical, England) and pulverized to a uniform particle size. The chemical modification was carried out by dispersing $20 \mathrm{~g}$ of the gum in $100 \mathrm{~mL}$ distilled water. Stirring was carried out for 30 minutes and the $\mathrm{pH}$ was adjusted to 8.0 with sodium hydroxide. Approximately $1.2 \mathrm{~g}$ of acetic anhydride was added to the slurry and the reaction was allowed to proceed for another $5 \mathrm{~min}$. The $\mathrm{pH}$ was adjusted to 4.5 with $0.5 \mathrm{M}$ hydrochloric acid and then filtered. The residue was washed four times with ethanol, dried in the oven and pulverized.

\section{Determination of physicochemical properties}

The following physicochemical properties were determined for both the native and modified gums:

\section{Viscosity}

Aqueous dispersion (2\% w/v) of each gum sample was made and left for one hour to hydrate.

The viscosities were then determined using a Brookfield viscometer model DV$11+$ Pro at

$50 \mathrm{rpm}$ and $100 \mathrm{rpm}$ using a spindle with code 04.

\section{Swelling Index}

Quantity (2.5 g) of each gum sample was poured into a $100 \mathrm{~mL}$ measuring cylinder and the volume was read as $\mathrm{V}_{1}$. Distilled water was then added gradually with the dispersion shaken thoroughly for 5 minutes. The dispersion was allowed to stand for 24 hours before the sedimentation volume was obtained and read as $\mathrm{V}_{2} \cdot{ }^{13}$ The swelling capacity was calculated thus:

Swelling capacity $=\mathrm{V}_{2} / \mathrm{V}_{1}$

$\mathrm{V}_{1}=$ volume occupied by the gum prior to hydration.

$\mathrm{V}_{2}=$ volume occupied by the gum after the hydration.

\section{Density Measurements}

Bulk and tapped densities were determined thus: Approximately $10 \mathrm{~g}$ of each gum sample was weighed and poured at an angle of $45^{\circ}$ through a funnel into a $100 \mathrm{~mL}$ glass measuring cylinder and the volume occupied by the sample was calculated using the height (h) of the sample in the measuring cylinder and the radius ( $r$ ) of the cylinder. Bulk density was calculated using the equation:

Bulk density $=\frac{\text { Mass }}{\pi r^{2} h}$ 
The tapped density was measured by applying 250 taps to $10 \mathrm{~g}$ of the gum samples in a measuring cylinder at a standardized rate of 25 taps per minute. The height of the powder bed and radius of the measuring cylinder were used in the calculation of volumes obtained and determinations were done in triplicates.

Carr's Index

The Carr's compressibility index was calculated from the results of bulk and tapped densities by using the equation below:

Carr's Index $=\frac{\text { Tapped density-Bulk density }}{\text { Tapped density }} X 100$

\section{Angle of repose}

This was determined using an open-ended cylinder placed on a wooden cork of known diameter. Approximately $10 \mathrm{~g}$ of the gum powder was allowed to flow through a funnel under the force of gravity into the previously placed cylinder. The content in the open-ended cylinder was then released to form a conical heap. The height of this heap was measured and the angle of repose was then calculated using the equation:

$\operatorname{Tan} \theta=\mathrm{h} / \mathrm{r}$

Where $h$ is the height of powder and $r$ is the radius of the base of the cone which is the radius of the wooden cork. The angle of repose was calculated from a mean of three determinations.

\section{Particle Size}

The particle size of the native and modified gums were determined using optical microscope (MT 330oEXII, MictotracBel, Japan). The photomicrographs were taken at $20 \mathrm{Kv}$.

\section{Preparation of Tablets}

Metronidazole tablets were prepared from formulations containing native Enterolobium gum, modified Enterolobium gum or HPMC at different concentrations as binders. Direct compression and wet granulation methods were used in preparing the tablets, using the formula:

$\begin{array}{ll}\text { Metronidazole } & 50 \%\end{array}$

Native gum/physically modified gum/chemically modified gum/HPMC $\quad 4 \%$ or $8 \%$

$\begin{array}{ll}\text { Corn starch } & 10 \%\end{array}$

Lactose to $100 \%$ 
In the direct compression method, a basic mixture of the above formula was prepared by dry mixing them in a mortar and pestle and then in a rotor mixer (Forster equipment Co. Ltd. whet stone, Leicester, England) for 10 minutes. From the powder mass, approximately $0.40 \mathrm{~g}$ was weighed out then compressed into tablets using a single punch carver hydraulic hand press (model c, carver Inc., Menomonee falls, Wisconsin, USA), a die of $10.5 \mathrm{~mm}$ in diameter at four different pressures $\left(0.5,0.75,1\right.$ and $\left.1.25 \mathrm{Nm}^{-2}\right)$. A $1 \% \mathrm{w} / \mathrm{v}$ dispersion of magnesium stearate in acetone was used to lubricate the punch and die surfaces before each compression.

Using the wet granulation method, A 4 or $8 \%$ dispersion of native gum, physically or chemically modified gum or HPMC was made and used as granulating fluid in the above stated formula. The granules formed were dried in the oven (Model DHG-9053A, Ocean Medical, England) at $50{ }^{\circ} \mathrm{C}$, allowed to cool and then stored in air-tight containers. Tablets were prepared from the granules following the methods described in direct compression.

\section{Evaluation of Tablets}

1. Tablet Properties

Uniformity of weights, thickness, crushing strength, tensile strength and friability were evaluated to determine the tablet properties.

2. Release Properties

\section{(a). Disintegration test}

The disintegration time for the tablets from each pressure in every batch was determined in distilled water at $37.0 \pm 0.2{ }^{\circ} \mathrm{C}$ using the DBK disintegration testing apparatus (DBK Instruments Mumbai, India). The time taken for the tablet to completely break down and pass through the mesh was recorded with determinations in triplicates.

\section{(b). Dissolution rate test}

The dissolution rate of the tablets was determined in $0.1 \mathrm{~N} \mathrm{HCl}$ using the DBK dissolution test apparatus (Type 40DRTo1, DBK Instruments Mumbai, India). A calibration curve was first plotted for the metronidazole powder. Each tablet was placed in a cylindrical basket of stainless steel wire mesh which was attached to a rotor that can be regulated to varying speed and suspended in a glass beaker containing $500 \mathrm{ml}$ of $0.1 \mathrm{~N} \mathrm{HCL}$. The glass beaker is in turn immersed in a water bath controlled at a temperature of $37 \pm 2{ }^{\circ} \mathrm{C}$. The $0.1 \mathrm{~N} \mathrm{HCl}$ was also heated and maintained at this temperature. The apparatus was then 
set to rotate at 100 rpm and $5 \mathrm{~mL}$ of the dissolution medium was removed at specific time intervals as well as replaced simultaneously with an equal volume of fresh dissolution medium to maintain a sink condition. The withdrawn sample (1 mL) was diluted to $10 \mathrm{mls}$ and the absorbance of the diluted samples was measured using the ultraviolet/visible spectrophotometer (Spectrumlab $752 \mathrm{~S} 12078$, Bicotek Ningbo Ltd., China)) at a wavelength of $265 \mathrm{~nm}$ and the drug concentration determined from the calibration curve.

The dissolution rate kinetics was calculated using the SolverDD, a Microsoft Excel add-in program. In order to determine the mechanism of drug release, the release data was fitted in a Korsemeyer-Peppas equation: ${ }^{14}$

$\log (\mathrm{Mt} / \mathrm{Mf})=\log \mathrm{k}+\mathrm{nLog} \mathrm{t}$

This equation describes drug release behaviour from polymeric systems. Mt is the amount of drug release at time $\mathrm{t}$, Mf is the amount of drug release after infinite time; $\mathrm{k}$ is a release rate constant incorporating the structural and geometric characteristics of the dosage form and $n$ is the diffusional exponent, which indicates the mechanism of drug release. For a cylinder-shaped matrix, the value of $\mathrm{n}=0.45$ indicates Fickian (case I) release; $>0.45$ but $<0.89$ for non-Fickian (anomalous) release; and $>0$ indicates a super case II type of release. The case II mechanism refers to the erosion of the polymer and anomalous transport (non-Fickian) refers to a combination of both diffusion and erosion-controlled drug release.

\section{Factorial Experimental Design}

A $2^{3}$ factorial experiment design, which required eight batches to be prepared, was used to determine the individual and interacting effects of the selected formulation variables on the mechanical and release properties of the tablets. This has been found very useful in determining the effect of various formulation factors on the characteristics of drug formulations ${ }^{15,16}$. Three independent process parameters: nature of polymer, concentration of polymer and processing technique were applied at two different levels. These parameter levels are summarized in Table 1. The sequence of the eight experiments was randomized. The purpose of using a full factorial experimental design was to carry out a complete study of the effects of the process parameters and their interactions, with the aid of a computer and suitable statistical software (Minitab@ 14.2). Table 1 shows the Independent process parameters and their levels. Lower Level was coded -1 while higher level was coded +1 . Nature of polymer was $X_{1}$, Concentration of polymer was $\mathrm{X}_{2}$ and processing technique was $\mathrm{X}_{3}$. 
Table 1: Factor combinations and values of Friability $(\mathrm{F})$, Tensile strength $(\mathrm{T})$ and Disintegration time (Dt) for tablets in the factorial experimental design

\begin{tabular}{ccccccc}
\hline Batch number & $\begin{array}{c}\text { Nature of } \\
\text { Polymer }\left(\mathbf{X}_{1}\right)\end{array}$ & $\begin{array}{c}\text { Concentration } \\
\text { of Polymer } \\
\left(\mathbf{X}_{2}\right)\end{array}$ & $\begin{array}{c}\text { Processing } \\
\text { technique } \\
\left(\mathbf{X}_{3}\right)\end{array}$ & $\begin{array}{c}\text { Tensile } \\
\text { Strength } \\
(\mathbf{K g F})\end{array}$ & Friability (\%) & $\begin{array}{c}\text { Disintegration } \\
\text { Time }(\mathbf{m i n})\end{array}$ \\
\hline 1 & -1 & -1 & -1 & 0.43 & 0.95 & 10 \\
2 & 1 & -1 & -1 & 0.63 & 1.97 & 15 \\
3 & -1 & 1 & -1 & 0.49 & 0.87 & 12 \\
4 & 1 & 1 & -1 & 0.63 & 1.99 & 15 \\
5 & -1 & -1 & 1 & 0.51 & 0.92 & 4.8 \\
7 & 1 & -1 & 1 & 0.9 & 0.99 & 14 \\
8 & -1 & 1 & 1 & 0.61 & 0.97 & 9.36
\end{tabular}

Key: -1: Low values / +1: High values

The effects of the various parameters on the mechanical and release properties of the tablets were compared by Student's t-test. At the 95\% confidence level, a $\mathrm{p}$ value lower than or equal to 0.05 was required for significance.

\section{RESULTS and DISCUSSION}

\section{Physicochemical Properties}

\section{Particle size}

Particle size has been postulated to affect absorption rate, uniformity of content, dissolution rate and stability of pharmaceutical formulations. ${ }^{17}$ The particles of the native gum were smaller and more irregularly shaped than the physically and chemically modified gums. The results therefore suggest that modification of the gums imparts increase in particle size with chemical modification having a greater increase (Table 2). Flow of materials is influenced by particle size because of the adhesion and cohesion phenomena which occur on the surface; small sized particles with high surface-to-mass ratio are cohesive and have poor flow while coarse particles are bigger in sizes and have better flow. The small particle size of the native gum could be of advantage to the formulation scientist, in the sense that it offers opportunity for modification according to the desired size. 
Table 2: Physicochemical Properties of the Polymers (Mean \pm s.d, $n=3$ )

\begin{tabular}{|c|c|c|c|c|}
\hline Materials & NG & PMG & CMG & HPMC \\
\hline Viscosity (cp) & $44.60 \pm 1.34$ & $20.35 \pm 2.45$ & $9.20 \pm 1.22$ & $25.55 \pm 4.10$ \\
\hline Bulk Density $\left(\mathrm{g} / \mathrm{cm}^{3}\right)$ & $0.61 \pm 0.05$ & $0.45 \pm 0.09$ & $0.53 \pm 0.12$ & $0.64 \pm 0.20$ \\
\hline $\begin{array}{l}\text { Tapped Density } \\
\qquad\left(\mathrm{g} / \mathrm{cm}^{3}\right)\end{array}$ & $0.78 \pm 0.09$ & $0.52 \pm 0.03$ & $0.65 \pm 0.08$ & $1.45 \pm 0.07$ \\
\hline Particle density & $1.71 \pm 0.51$ & $1.48 \pm 0.09$ & $1.40 \pm 0.55$ & $1.25 \pm 0.06$ \\
\hline Carrs' Index (\%) & $22.60 \pm 1.65$ & $13.96 \pm 3.45$ & $18.62 \pm 5.50$ & $14.19 \pm 2.25$ \\
\hline Hausner's Ratio & $1.29 \pm 1.01$ & $1.16 \pm 0.88$ & $1.23 \pm 0.54$ & $1.17 \pm 0.45$ \\
\hline Angle of repose $\left(^{\theta}\right)$ & $51.76 \pm 1.65$ & $49.60 \pm 2.50$ & $52.72 \pm 1.05$ & $56.05 \pm 1.58$ \\
\hline Swelling Index (\%) & $3.17 \pm 0.85$ & $1.18 \pm 0.54$ & $1.59 \pm 0.25$ & $2.58 \pm 2.45$ \\
\hline Particle size $(\mu \mathrm{m})$ & $18.01 \pm 3.65$ & $120.32 \pm 5.15$ & $210.10 \pm 4.45$ & $25.60 \pm 1.70$ \\
\hline
\end{tabular}

\section{Angle of repose}

Angle of repose is a characteristic of the internal friction or cohesion of the particles. The value of the angle of repose will be high if the powder is cohesive and low if the powder is non-cohesive. ${ }^{18}$ It is an indirect method of quantifying powder flowability because of their relationship with interparticulate cohesion and has been used in several branches of science to characterize the flow properties of solids. It is worthy of note that angle of repose is not an intrinsic property of the powder i.e. it is to a large extent dependent upon the method used to form the cone of the powder. Angle of indicates excellent flow; represents good flow; indicates fair flow; represents passable flow; indicates poor flow while indicates very poor flow and indicates very very poor flow property. ${ }^{19}$

From the results, it can be observed that the gums in both native and modified forms have high values of angle of repose which indicates poor flow properties. The ranking was HPMC > chemically modified gum > native gum $>$ physically modified gum (Table 2). This indicates that physical modification could slightly improve the flow.

\section{Density Measurements}

The bulk and tapped densities give an insight of the packing and arrangement of the particles and the compaction profile of a material. Various factors can affect the bulk and tapped densities of a material such as cohesiveness due to surface forces, particle size and distribution, particle shape and true density of solids ${ }^{19}$, ${ }^{20}$. It is an important property in packaging and powder handling. Powders with 
large bulk density are heavy powders while powders with low bulk density are light powders. In a free-flowing powder, the inter -particulate interactions are less significant and the bulk and tapped densities will be close in value. For poor flowing powder, inter-particulate interaction is greater and a great difference is noticed between the bulk and tapped density. The rank order for bulk density is native gum $>$ chemically modified gum $>$ physically modified gum (Table 2 ). Tapped density also followed this order. The difference in the bulk and tapped density of native and chemically modified gum was higher than that of physically modified gum showing that the former had a higher inter-particulate interaction hence a poor flowing powder. This shows that the chemically modified gum was more compact than the physically modified gum and less compact than the native gum.

\section{Swelling Properties}

Natural gums are often known for their good swelling properties and their ability to reach a steady swelling state in a short time by the entrapment of large amounts of water between their chains and branches. ${ }^{18,21}$ The rank order of swelling index among the polymers was native gum $>$ HPMC $>$ chemically modified gum $>$ physically modified gum with values of $3.17>2.58>1.59>1.18$, respectively (Table 2). This shows that modification of the gum reduced the swelling of the gum. This could be of importance in the formulation of sustained release delivery systems when reduced swelling may delay disintegration and subsequently prolong drug delivery.

\section{Viscosity}

The viscosity profile of the gum both native and modified ones showed an increase in the viscosity with an increase in the revolution per minute (rpm) used which are 50 and 10orpm. There was also a decrease in viscosity with increase in time. The order of viscosity is native gum > HPMC > physically modified $>$ chemically modified gum (Table 2 ). The modified gums had a low swelling index (capacity) due to poor interaction between their particles and water molecules; this could have been responsible for the low viscosity when compared with native gum ${ }^{21,22}$.

\section{Organoleptic Properties}

The extracted gum was observed to be brown in colour and with a pleasant odour. However, the physically modified gum had a darker shade of brown colour while the chemically modified polymer was greyish. These properties suggest acceptability, both in term of colour and odour. The change in colour from brown to grey after chemical modification is probably due to the acetylation process. 


\section{Tablet Properties}

\section{Crushing Strength}

Crushing strength provides a measure of the mechanical strength of the tablets and there are official requirements for compressed tablets ${ }^{23}$ but there are no limits for the acceptance or rejection of tablet formulation due to crushing strength; this is probably because the desired crushing strength is largely dependent on the intended use of tablet. ${ }^{23,24}$ Results obtained showed that increase in concentration of the gums (native and Modified) resulted in an increase in the crushing strength of the respective tablets and this increase corresponds to the increase in compression pressure used (Table $3 \& 4$ ).

Table 3: Properties of Tablets Prepared by Direct Compression (Mean $\pm s . d, n=3$ )

\begin{tabular}{|c|c|c|c|c|c|c|}
\hline $\begin{array}{c}\text { Polymer/ } \\
\text { Concentration } \\
(\%)\end{array}$ & $\begin{array}{c}\text { Compression } \\
\text { Pressure } \\
\mathrm{MNm}^{-2}\end{array}$ & $\begin{array}{c}\text { Mean } \\
\text { Weight (g) }\end{array}$ & $\begin{array}{l}\text { Thickness } \\
\text { (mm) }\end{array}$ & $\begin{array}{c}\text { Crushing } \\
\text { Strength }(\mathrm{KgF})\end{array}$ & $\begin{array}{l}\text { Friability } \\
(\%)\end{array}$ & $\begin{array}{l}\text { Disintegration } \\
\text { Time (sec) }\end{array}$ \\
\hline \multirow{2}{*}{$N G / 4$} & 0.50 & $0.19 \pm 0.03$ & $2.13 \pm 0.26$ & $6.00 \pm 1.02$ & $1.04 \pm 0.13$ & $8.00 \pm 6.35$ \\
\hline & 1.25 & $0.20 \pm 0.02$ & $1.99 \pm 0.11$ & $15.12 \pm 2.86$ & $0.91 \pm 1.55$ & $11.00 \pm 8.62$ \\
\hline \multirow{2}{*}{$N G / 8$} & 0.50 & $0.19 \pm 0.01$ & $2.11 \pm 0.10$ & $15.98 \pm 3.29$ & $0.98 \pm 1.10$ & $10.00 \pm 4.65$ \\
\hline & 1.25 & $0.21 \pm 0.12$ & $2.08 \pm 0.11$ & $16.55 \pm 2.55$ & $0.92 \pm 0.18$ & $12.00 \pm 8.39$ \\
\hline \multirow{2}{*}{$\mathrm{PMG} / 4$} & 0.50 & $0.19 \pm 0.11$ & $2.03 \pm 0.09$ & $15.25 \pm 0.72$ & $0.75 \pm 1.18$ & $11.00 \pm 5.19$ \\
\hline & 1.25 & $0.19 \pm 0.22$ & $2.00 \pm 0.14$ & $18.94 \pm 5.05$ & $0.72 \pm 1.58$ & $14.00 \pm 3.35$ \\
\hline \multirow{2}{*}{ PMG/8 } & 0.50 & $0.21 \pm 0.05$ & $2.02 \pm 1.25$ & $16.20 \pm 0.82$ & $0.78 \pm 1.20$ & $13.00 \pm 7.13$ \\
\hline & 1.25 & $0.20 \pm 0.09$ & $2.01 \pm 0.85$ & $17.98 \pm 0.55$ & $0.70 \pm 1.18$ & $15.00 \pm 4.25$ \\
\hline \multirow{2}{*}{$\mathrm{CMG} / 4$} & 0.50 & $0.20 \pm 0.10$ & $2.05 \pm 1.45$ & $15.23 \pm 0.15$ & $1.98 \pm 1.50$ & $13.00 \pm 1.55$ \\
\hline & 1.25 & $0.20 \pm 0.15$ & $2.00 \pm 0.18$ & $21.52 \pm 0.24$ & $1.99 \pm 2.21$ & $15.00 \pm 1.83$ \\
\hline \multirow{2}{*}{$\mathrm{CMG} / 8$} & 0.50 & $0.19 \pm 0.21$ & $2.08 \pm 1.45$ & $17.62 \pm 0.11$ & $1.92 \pm 1.90$ & $14.00 \pm 4.15$ \\
\hline & 1.25 & $0.21 \pm 0.16$ & $2.02 \pm 0.62$ & $23.02 \pm 0.14$ & $1.99 \pm 5.21$ & $15.00 \pm 6.12$ \\
\hline \multirow{2}{*}{$\mathrm{HPMC} / 4$} & 0.50 & $0.19 \pm 0.15$ & $2.00 \pm 1.85$ & $15.20 \pm 0.82$ & $0.92 \pm 2.90$ & $13.00 \pm 3.35$ \\
\hline & 1.25 & $0.21 \pm 0.10$ & $1.97 \pm 0.12$ & $17.88 \pm 0.15$ & $0.99 \pm 4.21$ & $15.00 \pm 3.06$ \\
\hline \multirow{2}{*}{ HPMC/8 } & 0.50 & $0.20 \pm 0.30$ & $1.99 \pm 1.15$ & $15.65 \pm 0.22$ & $0.87 \pm 2.10$ & $13.00 \pm 2.35$ \\
\hline & 1.25 & $0.20 \pm 0.19$ & $1.96 \pm 0.20$ & $16.98 \pm 0.12$ & $0.86 \pm 5.11$ & $15.00 \pm 1.62$ \\
\hline
\end{tabular}

Table 4: Properties of Tablets Prepared by Wet Granulation (Mean $\pm s . d, n=3$ )

\begin{tabular}{|c|c|c|c|c|c|c|}
\hline $\begin{array}{c}\text { Polymer/ } \\
\text { Concentration } \\
\mathbf{( \% )}\end{array}$ & $\begin{array}{c}\text { Compression } \\
\text { Pressure } \\
\mathbf{M N m}^{-2}\end{array}$ & $\begin{array}{c}\text { Mean } \\
\text { Weight }(\mathbf{g})\end{array}$ & $\begin{array}{c}\text { Thickness } \\
\mathbf{( m m )}\end{array}$ & $\begin{array}{c}\text { Crushing } \\
\text { Strength } \\
\mathbf{( K g F )}\end{array}$ & $\begin{array}{c}\text { Friability } \\
\mathbf{( \% )}\end{array}$ & $\begin{array}{c}\text { Disintegration } \\
\text { Time (sec) }\end{array}$ \\
\hline $\mathrm{NG} / 4$ & 0.50 & $0.20 \pm 0.10$ & $2.50 \pm 0.16$ & $12.00 \pm 7.12$ & $0.95 \pm 6.15$ & $249.00 \pm 3.75$ \\
\hline & 1.25 & $0.20 \pm 0.20$ & $2.22 \pm 5.35$ & $22.12 \pm 8.60$ & $0.94 \pm 5.51$ & $292.00 \pm 7.22$ \\
\hline $\mathrm{NG} / 8$ & 0.50 & $0.19 \pm 0.11$ & $2.31 \pm 0.17$ & $15.12 \pm 9.10$ & $0.91 \pm 3.33$ & $525.00 \pm 6.15$ \\
\hline & 1.25 & $0.21 \pm 0.42$ & $2.08 \pm 0.22$ & $26.15 \pm 7.51$ & $0.96 \pm 8.32$ & $570.00 \pm 9.70$ \\
\hline $\mathrm{PMG} / 4$ & 0.50 & $0.20 \pm 0.15$ & $2.45 \pm 5.18$ & $14.05 \pm 0.28$ & $0.82 \pm 5.68$ & $588.00 \pm$ \\
& 1.25 & $0.21 \pm 0.22$ & $2.10 \pm 0.16$ & $22.16 \pm 5.75$ & $0.92 \pm 5.18$ & $615.00 \pm 7.80$ \\
\hline $\mathrm{PMG} / 8$ & 0.50 & $0.20 \pm 0.15$ & $2.40 \pm 1.70$ & $16.80 \pm 7.12$ & $0.89 \pm 2.50$ & $640.00 \pm 9.70$ \\
\hline
\end{tabular}


The increase in hardness might be due to the fact that stronger inter-particulate bonds were formed with increasing polymer concentration. Ranking order among the formulations was $\mathrm{CMG} 8>\mathrm{CMG} 4>\mathrm{PMG} 8>\mathrm{PMG} 4>\mathrm{HPMC} 8>$ HPMC4 > NG8 > NG4. Crushing strength was generally high in tablets prepared by wet granulation than those prepared by direct compression method. This suggests that the addition of water in wet granulation allows for wetting, thereby producing greater penetration of the polymer. The gums would therefore serve a better binding agent in the presence of water than in their dry states.

\section{Tensile Strength}

Tensile strength is the resistance of a material to breaking under tension; it is a characteristic of internal friction or cohesion of particles and calculated from crushing strength i.e.

$\mathrm{T}=2 \mathrm{~F} / \Pi \mathrm{dt}$

Where $\mathrm{F}$ is the crushing strength, $\mathrm{d}$ and $\mathrm{t}$ are the tablet diameter and thickness respectively.

Tensile strength provides a more fundamental measure of the mechanical strength of the compacted material and takes into account the geometry of the tablet. If the tablets fail in tension, the breaking force can be used to calculate the tensile strength. It is a measure of mechanical property of tablet. ${ }^{25}$ The trend observed in the calculated tensile strength of the tablets was same with the crushing strength.

\section{Friability}

Friability is another mechanical property which evaluates the ability of tablets to withstand abrasion in packing, handling and transporting. It is regarded as attrition resistance method in determining the mechanical property of a tablet. Unlike crushing strength that is a bulk deformation of the tablet, friability is a surface deformation of the tablet which may be enhanced by the morphology of the tablet. The rougher the surface of the tablet, the more friable it will be ${ }^{25,26}$. For compressed tablets, the percentage loss in weight of less than or equal to $1 \%$ is usually considered acceptable ${ }^{23}$.

From the results obtained (Tables 3 and 4), tablets prepared with wet granulation method generally passed the friability. However, tablets containing chemically modified polymers (CMG 4 and CMG 8) had friability values of greater than $1 \%$, while the values were less than $1 \%$ in all other formulations. This is an indication that irrespective of the form of the polymer, wet granulation method will produce tablets of better mechanical strength. However, if direct compres- 
sion is the desired method of tablet production, physical modification should be considered. Furthermore, it was observed that the percentage weight loss generally reduced with increase in binder concentration and compression pressure; this is probably due to more binder molecules being made available together with the fact that stronger compacts are formed with higher compression pressure, thus producing tablets with less rough surfaces.

\section{Release Properties}

\section{Disintegration Time}

Disintegration is a crucial step in release of drugs from immediate release dosage forms. It is useful for assessing the potential importance of formulation and process variables on the biopharmaceutical properties of the tablet and as a control procedure to evaluate the quality reproducibility of the tablet during production ${ }^{26}$. The rate of disintegration is influenced by the rate of influx of water into the tablets which is also dependent on the porosity of the tablets. Disintegration time measures the time required for the tablet to crumble into particles and it is a necessary condition for dissolution and could be the rate determining step in the process of drug absorption. The British Pharmacopoeia stipulated a disintegration time of not more than 15 minutes for uncoated tablets. ${ }^{23}$ From the result obtained, it was observed that the tablets containing native gum, modified gums and HPMC had disintegration time less than fifteen minutes and thus fell within the acceptable limit specified in the British Pharmacopeia. The ranking was native gum $<$ Physically modified gum $<$ chemically modified gum $>$ HPMC and the disintegration time were observed to increase with increase in the compression pressure and also with increase in the concentration of the binder. The results (Tables 3 and 4) therefore suggest that the gum, both in its native and modified form could produce tablets of acceptable disintegration time. The disintegration time of tablets produced by wet granulation is generally longer than those produced by direct compression ( $\mathrm{p}<$ 0.05); this is probably due to the water influx which occurred in wet granulation, thereby leading to creation of stronger bonds between the materials ${ }^{27}$.

\section{Drug Release}

The dissolution of a drug from the dosage form is one of the important parameters that determine bioavailability of that drug ${ }^{1}$. Fundamentally, this process is controlled by the relative affinities between the molecules of the solid substance and those of the solvent. The factors that affect dissolution include type and concentration of binder, mechanical properties of tablets, surface area, distance of diffusion, solubility of the drug, manufacturing processe ${ }^{18}$. Dissolution rate 
test is therefore used to evaluate the potential effect of formulation and to ensure the performance of the preparation under in-vivo condition. The dissolution rate profiles of the formulations are shown in Figures 1 and 2.

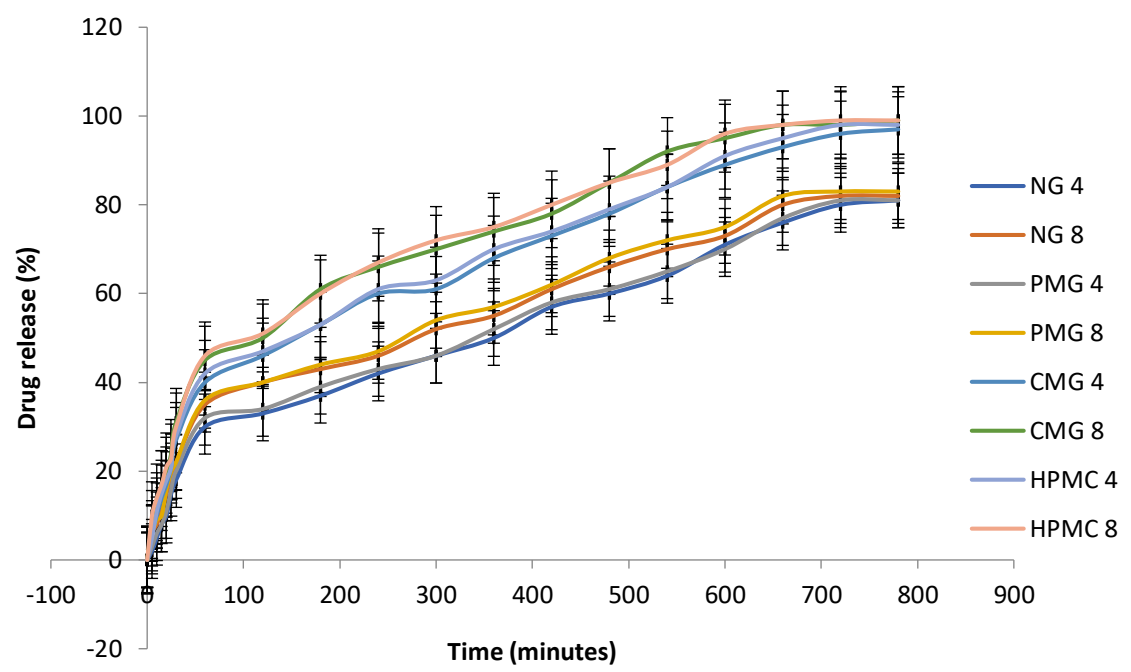

Figure 1: Release Profile for Tablets Produced by Direct Compression (mean values plotted; $\mathrm{n}=3$, with standard error bars on the plots)

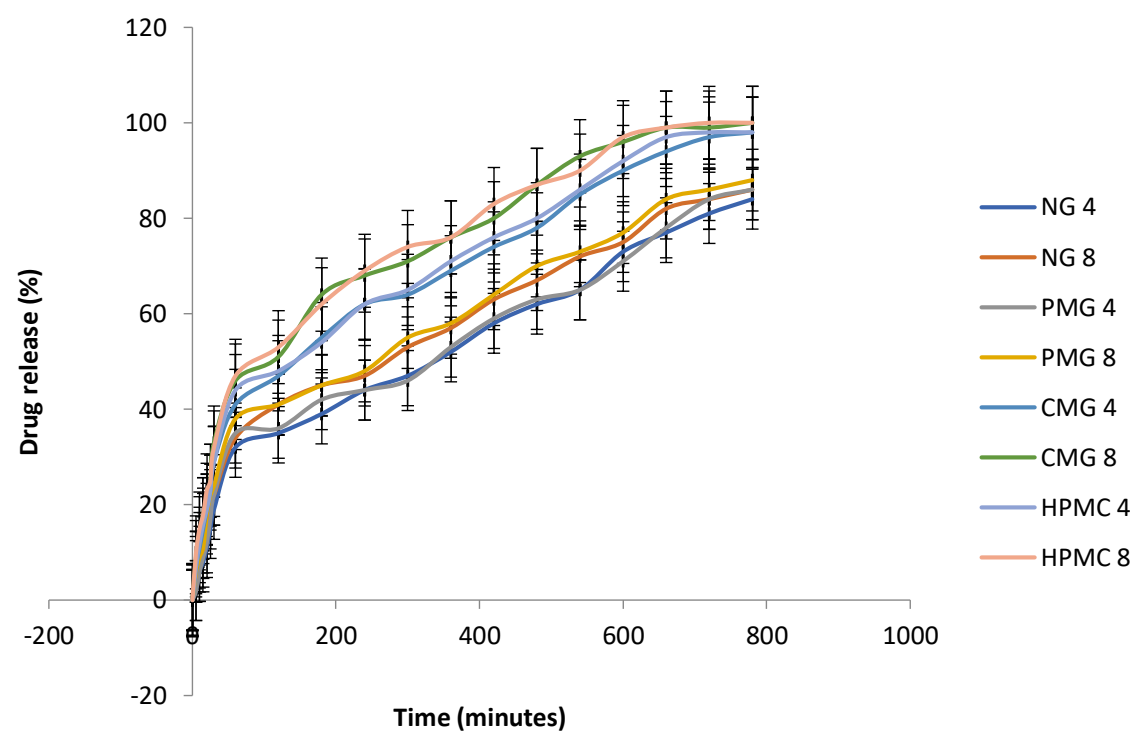

Figure 2: Release Profile for Tablets Produced by Wet Granulation (mean values plotted; $n=3$, with standard error bars on the plots) 
All the formulations exhibited similar trends in their drug release; an initial gradual release up to 30 minutes followed by a sustained release for more than 12 hours. Similar release profile was observed in a previous study on Enterolobium gum ${ }^{1}$. All the formulations showed a high drug release of $81-99 \%$. These results suggest that the gum in its native and modified forms has similar release profile and capable of sustaining the drug for up to 12 hours. The chemically modified gum formulations (CMG 4 and CMG 8) showed the highest drug release, almost same with formulations containing HPMC; the ranking was HPMC $8>\mathrm{HPMC}_{4}>\mathrm{CMG} 4>\mathrm{CMG} 8>\mathrm{PMG} 4>>\mathrm{PMG} 8>\mathrm{NG} 4>$ NG 8 . The difference between drug release in formulations containing native and physically modified gum is not significant while a significant difference was observed between formulations containing the chemically modified and those containing the native and physically modified gum. This implies that chemical modification had a significant effect on the drug release profile of the gum while physical modification does not. The drug release profiles of tablets prepared with direct compression (Fig. 1) and wet granulation (Fig. 2) were similar; this shows that tablet processing may not significantly affect drug release profile of tablets prepared with the gum.

\section{Mechanism of Drug Release}

The physicochemical properties of the drug and the polymer have been shown to govern the release of drug from formulations and this which could affect their release kinetics. The drug release kinetics of the different formulations were fitted into zero order, first order, Higuchi, Hixson-Crowell, Hopfenberg, Korsmeyer-Pepppas ${ }^{28,29,30,14 .}$

The constants of release kinetic and coefficient of correlation $\left(\mathrm{R}^{2}\right)$ were obtained from slopes of plots by linear regression analysis. All the formulations have the highest value of $\mathrm{R}^{2}$ in the in the Korsmeyer-Pepppas equation (Tables 5 and 6). This indicates that the drug- release from all the formulations is not concentration dependent. In order to determine the mechanism of drug release, the release data was fitted in a Korsemeyer-Peppas equation, which is suitable for the description of drug release from polymeric materials. From the equation, the value of $\mathrm{n}$ for each formulation was taken. When $\mathrm{n}$ is 0.430 or less, it indicates release is by diffusion mechanism. When $\mathrm{n}$ is 0.85 , the mechanism of release is swelling controlled and when $\mathrm{n}$ is between 0.430 and 0.85 , the mechanism of drug release is by both diffusion and swelling controlled mechanisms and this is termed anomalous. The values of $\mathrm{n}$ for formulations containing the gum (native or modified) at $4 \%$ concentration range between 0.432 and 0.485 (Tables 5 and 6); which indicates that the mechanism of release from these formulations is by 
both diffusion and swelling. When the gum (native or modified) was used at the $8 \%$ concentration, values of $\mathrm{n}$ for the formulations were less than 0.430 (Tables 5 and 6), indicating that the mechanism of release is by diffusion.

Table 5: In vitro Release Kinetics from Formulations Prepared by Direct Compression

\begin{tabular}{|c|c|c|c|c|c|c|c|}
\hline \multicolumn{8}{|c|}{ Direct Compression } \\
\hline \multirow[t]{2}{*}{ Batch } & \multirow{2}{*}{$\begin{array}{c}\text { Zero } \\
\text { order } \\
\mathrm{R}^{2}\end{array}$} & \multirow{2}{*}{$\begin{array}{c}\text { First } \\
\text { order } \\
\mathrm{R}^{2}\end{array}$} & \multirow{2}{*}{$\begin{array}{l}\text { Higuchi } \\
\mathrm{R}^{2}\end{array}$} & \multirow{2}{*}{$\begin{array}{l}\text { Hixson-Crowell } \\
\qquad \mathrm{R}^{2}\end{array}$} & \multirow{2}{*}{$\begin{array}{c}\text { Hopfenberg } \\
\mathrm{R}^{2}\end{array}$} & \multicolumn{2}{|c|}{ Korsmeyer } \\
\hline & & & & & & $\mathrm{R}^{2}$ & $\mathrm{~N}$ \\
\hline NG 4 & 0.765 & 0.869 & 0.976 & 0.840 & 0.869 & 0.976 & 0.485 \\
\hline NG 8 & 0.649 & 0.805 & 0.964 & 0.761 & 0.805 & 0.977 & 0.425 \\
\hline PMG 4 & 0.730 & 0.846 & 0.970 & 0.813 & 0.846 & 0.973 & 0.465 \\
\hline PMG 8 & 0.656 & 0.815 & 0.966 & 0.771 & 0.815 & 0.978 & 0.427 \\
\hline CMG 4 & 0.667 & 0.869 & 0.972 & 0.818 & 0.869 & 0.982 & 0.432 \\
\hline CMG 8 & 0.614 & 0.876 & 0.964 & 0.815 & 0.876 & 0.982 & 0.412 \\
\hline HPMC 4 & 0.655 & 0.866 & 0.969 & 0.814 & 0.866 & 0.981 & 0.428 \\
\hline HPMC 8 & 0.610 & 0.880 & 0.966 & 0.819 & 0.880 & 0.986 & 0.410 \\
\hline
\end{tabular}

Table 6: In vitro Release Kinetics from Formulations Prepared by Wet Granulation

\begin{tabular}{|c|c|c|c|c|c|c|c|}
\hline \multicolumn{8}{|c|}{ Direct Compression } \\
\hline \multirow[t]{2}{*}{ Batch } & \multirow{2}{*}{$\begin{array}{c}\text { Zero } \\
\text { order } \\
\mathrm{R}^{2}\end{array}$} & \multirow{2}{*}{$\begin{array}{c}\text { First } \\
\text { order } \\
\mathrm{R}^{2}\end{array}$} & \multirow{2}{*}{$\begin{array}{c}\text { Higuchi } \\
\mathrm{R}^{2}\end{array}$} & \multirow{2}{*}{$\begin{array}{c}\text { Hixson-Crowell } \\
\mathrm{R}^{2}\end{array}$} & \multirow{2}{*}{$\begin{array}{c}\text { Hopfenberg } \\
\mathrm{R}^{2}\end{array}$} & \multicolumn{2}{|c|}{ Korsmeyer } \\
\hline & & & & & & $\mathrm{R}^{2}$ & N \\
\hline NG 4 & 0.745 & 0.859 & 0.972 & 0.827 & 0.859 & 0.973 & 0.474 \\
\hline NG 8 & 0.644 & 0.809 & 0.968 & 0.763 & 0.809 & 0.982 & 0.421 \\
\hline PMG 4 & 0.686 & 0.815 & 0.955 & 0.778 & 0.815 & 0.961 & 0.447 \\
\hline PMG 8 & 0.624 & 0.793 & 0.956 & 0.746 & 0.793 & 0.974 & 0.414 \\
\hline CMG 4 & 0.620 & 0.853 & 0.966 & 0.794 & 0.853 & 0.983 & 0.444 \\
\hline CMG 8 & 0.588 & 0.873 & 0.959 & 0.809 & 0.873 & 0.983 & 0.402 \\
\hline HPMC 4 & 0.622 & 0.854 & 0.964 & 0.796 & 0.853 & 0.982 & 0.414 \\
\hline HPMC 8 & 0.584 & 0.878 & 0.961 & 0.814 & 0.878 & 0.986 & 0.400 \\
\hline
\end{tabular}

\section{Factorial Experimental Design}

The individual effects of the three parameters used in the factorial experiment; nature of polymer $\left(\mathrm{X}_{1}\right)$, concentration of polymer $\left(\mathrm{X}_{2}\right)$ and processing technique $\left(\mathrm{X}_{3}\right)$ on the response variables are presented in Table 7. A positive qualitative effect signifies that the response variable has increased in magnitude, while a negative effect shows a decrease ${ }^{15,16}$. 
Table 7: Individual Coefficients of Process Parameters for Tablet Properties

$\begin{array}{ccccc}\text { Factor } & \text { Coefficient } & \begin{array}{c}\text { Tensile Strength } \\ \mathbf{( K g F )}\end{array} & \begin{array}{c}\text { Friability } \\ \mathbf{( \% )}\end{array} & \begin{array}{c}\text { Disintegration Time } \\ \mathbf{( m i n )}\end{array} \\ \mathrm{X}_{1} & \text { Effect } & 0.265 & 0.5550 & 5.427 \\ \mathrm{X}_{2} & \text { Effect } & 0.050 & -0.0050 & 1.607 \\ \mathrm{X}_{3} & \text { Effect } & 0.195 & -0.4800 & -2.493\end{array}$

Nature of polymer $\left(\mathrm{X}_{1}\right)$ had the highest effect on disintegration time. The ranking for the effect of $\mathrm{X}_{1}$ on the response variables was Disintegration time $>$ Friability $>$ Tensile strength. Values of the effects were positive on all the variables showing that as nature of polymer changed from native gum to modified gum, values of tensile strength, friability and disintegration time increased. It can also be inferred that modification of the gum would improve the mechanical properties of tablets. However, the difference in the disintegration time of formulations containing modified and native gum was not significant.

The effect of concentration of polymer was highest on disintegration time; ranking was Disintegration time $>$ Tensile strength $>$ Friability. Positive effects were obtained in disintegration time and tensile strength while the effect on friability was negative. These results show that increasing the concentration of gums from $4 \%$ to $8 \%$ improved the mechanical strength of the tablets. The negative value observed for friability reinforced the increased binding effect of increased polymer concentration leading to decreased tablet friability.

The ranking of effect of Processing technique $\left(\mathrm{X}_{3}\right)$ on the response variables was Disintegration time $>$ Friability $>$ Tensile strength. The effect was positive on tensile strength and negative on both disintegration time and friability. This suggests that changing the processing technique from direct compression to wet granulation produced tablets of higher tensile strength due increased bonds formed. The water influx which enhances stronger bonds in wet granulation could also be responsible for the reduction in the time taken for the tablet to disintegrate ${ }^{29,30}$.

Tensile strength was affected most by the parameter $\mathrm{X}_{1}$ (Figures 3 and 4 ). The rank order for effect of the parameters was $X_{1}>X_{3}>X_{2}(p<0.05)$. Similar trend was observed in friability and disintegration time. This indicates that as parameters changed from low to high level (native gum to modified gum; $4 \%$ to 8\% polymer concentration; direct compression to wet granulation) the values of tensile strength, friability and disintegration time increased. This shows that when the parameters are applied at the high levels, improve tensile strength and friability of tablets with prolonged disintegration time may be obtained. It 
is noteworthy that the prolonged disintegration time is within the officially acceptable limit for compressed tablets ${ }^{23}$.

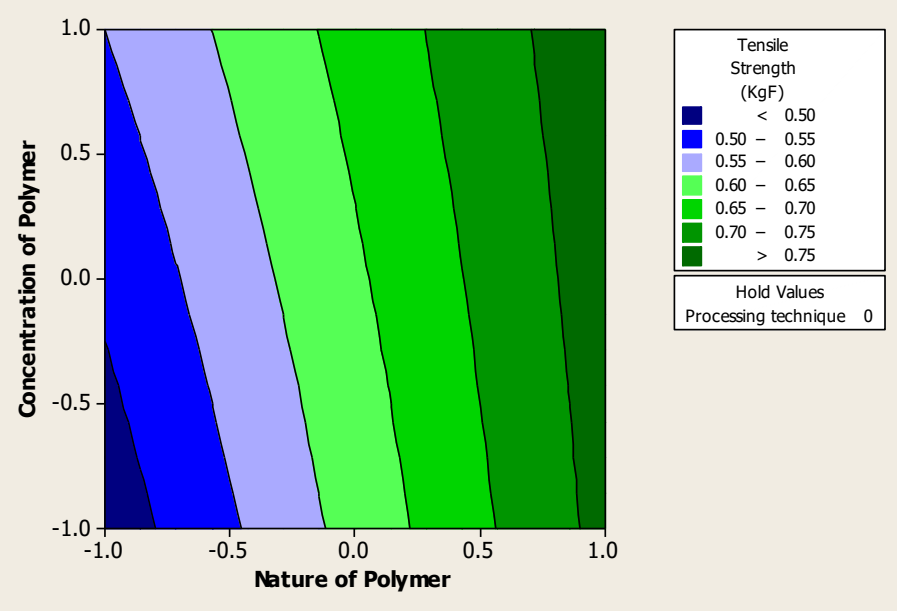

Figure 3: Contour plot of the effect of Concentration and Nature of Polymer on the Tensile strength of tablet formulations

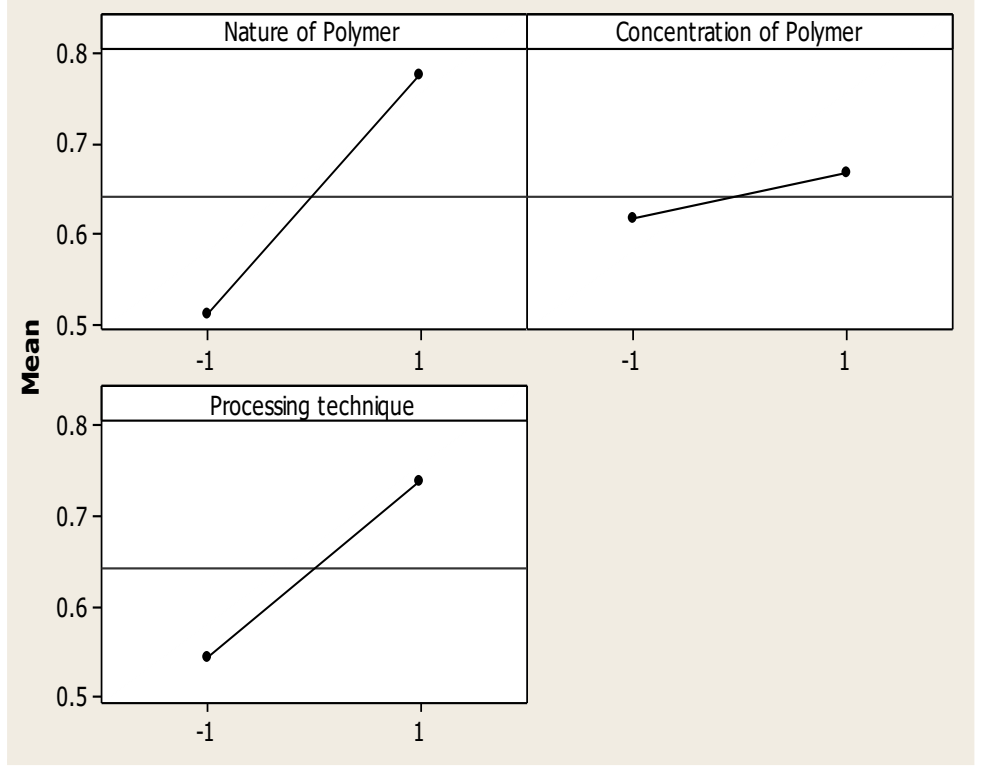

Figure 4: The main effect plots of the different variables on the tensile strength of the tablet formulations 
Values of the interaction coefficient are shown in Table 8. Rank orders for the interaction effects are $\mathrm{X}_{1} \mathrm{X}_{3}>\mathrm{X}_{1} \mathrm{X}_{2}>\mathrm{X}_{2} \mathrm{X}_{3}$ for tensile strength; $\mathrm{X}_{1} \mathrm{X}_{3}>\mathrm{X}_{2} \mathrm{X}_{3}>\mathrm{X}_{1} \mathrm{X}_{2}$ for friability and $\mathrm{X}_{1} \mathrm{X}_{2}>\mathrm{X}_{1} \mathrm{X}_{3}>\mathrm{X}_{2} \mathrm{X}_{3}$ for disintegration time. The results indicate that interaction between nature of polymer and processing technique had the greatest effect on the mechanical properties of the tablets while the interaction between nature and concentration of polymer had the greatest effect on the release property.

Table 8: Interaction Coefficients of Process Parameters for Tablet Properties

$\begin{array}{lcccc}\text { Factor } & \text { Coefficient } & \begin{array}{c}\text { Tensile Strength } \\ (\mathbf{K g F})\end{array} & \begin{array}{c}\text { Friability } \\ (\%)\end{array} & \begin{array}{c}\text { Disintegration Time } \\ (\mathbf{m i n})\end{array} \\ \mathrm{X}_{1} \mathrm{X}_{2} & \text { Effect } & -0.030 & 0.010 & -1.672 \\ \mathrm{X}_{1} \mathrm{X}_{3} & \text { Effect } & 0.095 & -0.515 & 1.428 \\ \mathrm{X}_{2} \mathrm{X}_{3} & \text { Effect } & 0.020 & 0.025 & 0.608\end{array}$

Furthermore the results show that the highest level of factor-factor interaction occurred between $\mathrm{X}_{1}$ and $\mathrm{X}_{2}$. The nature of a polymer has been reported to influence greatly its plastoelastic properties ${ }^{31}$ and this could in turn affect the mechanical properties of tablets. In the work of Ayorinde and Itiola (2010), ${ }^{16}$ it was shown that the effect of concentration of binder is strongly related to the nature of binder employed in the formulation. Thus, the interaction between the nature and concentration produced the greatest effect on the mechanical properties of tablets.

The suitability of Enterolobium gum as a formulation excipient in metronidazole tablet formulations has been determined. Gum modifications, concentration of polymer and the processing technique affect the mechanical and release properties of tablets. This type of study will be valuable in appropriately selecting and combining formulation variables in order to achieve desired formulation objectives.

\section{CONFLICT OF INTEREST:}

The authors hereby declare that they do not have any conflict of interest. 


\section{REFERENCES}

1. Ayorinde JO, Odeniyi MA, Bansal AK. Evaluation of two novel plant gums for bioadhesive microsphere and sustained- release formulations of metformin hydrochloride. Polim Med. 2017; 47(1): 13 - 23 .

2. Adetogun EA, Alebiowu G. Properties of Delonix regia seed gum as a novel tablet binder. Acta pol Pharm drug. 2009; 66(4): 433 - 438.

3. Samia EA, Babitar EM, Karamalla. Analytical studies on gum exudates of Angeissus leiocarpus. Pakistan nutr. 2009; 8(6): $782-786$.

4. Ayorinde JO, Itiola OA, Odeku OA, Odeniyi MA. Influence of binder type and process parameters on the compression properties and microbial survival in diclofenac tablet formulations. Braz J Pharm Sci. 2011; 47(4): 845 - 854 .

5. Ayorinde JO, Odeniyi MA. Evaluation of the suspending properties of new plant gum in Sulphamethoxazole formulations. Int J Pharmacol Pharm Tech. 2012; 1(2): 47-50.

6. Jani GK, Goswami JM, Prajapati VD. Studies on formulation and evaluation of new superdisintegrants for dispersible tablets. Int J Pharm Excip. 2oo5: 2; 37-43.

7. Ayorinde JO, Odeniyi MA. Disintegrant properties of native and modified metronidazole tablet formulations. Afri J Biomed Res. 2014; 17(3): 143- 152.

polymers in

8. Kavlani N, Sharma V, Singh L. Various technique for the modification of starch and the applications of its derivatives. Int Res J Pharm. 2012; 3 (5): 7 - 12.

9. Vatanasuchart N, Naivikul O, Charoenrein S. Molecular properties of cassava starch modified with different uv irradiatons to enhance baking expansion. Carbohydr Polym, 2005; 61: $80-87$.

10. Khan MA, Bhattacharia SK, Kader MA. Preparation and characterization of ultraviolet (uv) radiation cured biodegradable films of sago starch/PVA blend. Carbohydr Polym. 2oo6; 63: $500-506$.

11. Ayorinde JO, Effiong DE, Odeniyi MA. Design and evaluation of oral dissolving films of chlorpheniramine from native and modified Enterolobium cyclocarpum gum. Afr J Biomed Res. 2018; 21: 175 - 182.

12. Ayorinde JO, Odeniyi, MA. Solid state characterization of two novel gums from Cedrela odorata and Enterolobium cyclocarpum. J Pharm Invest. 2017; 48(4): 487 - 496.

13. Ayorinde JO, Balogun-Agbaje O, Odeniyi MA. Formulation and evaluation of oral dissolving films of amlodipine besylate using blends of starches with hydroxypropyl methyl cellulose. Polim Med. 2016: 46(1): 45 - 51 .

14. Korsmeyer RW, Gurny RE, Doelker EP, Buri NA, Peppas NA. Mechanisms of solute release from porous hydrophilic polymers. Int J Pharm. 1983; 15: 25-35.

15. Odeniyi MA, Jaiyeoba KT. Optimization of ascorbic acid tablet formulations containing hydrophilic polymers. Farmacia. 2009; 57 (2): 157-166.

16. Ayorinde JO, Itiola OA. Individual and interacting effects of formulation variables on the tensile strength and microbial survival in diclofenac tablets. Archiv Pharm Res. 2o1o; 33(3): $395-403$.

17. Ebere IO, Anthony OO, Kunle OO. Solid state characterization of Anacardium occidentale gum. Res J Sci Eng Tech. 2012; 4(19): 3709-3719.

18. Warsi MH, Ahmad FJ, Rankell AS, Lieberma HA, Schiffmann RF. Drying. In: Khar RK, 
Vyas SP, Ahmad FJ, Jain GK, editors. In The Theory and Practice of Industrial Pharmacy. 4th ed. India: CBS Publishers and Distributors; 2013. p. 89-107.

19. Arul K, Palanisamy S, Rajasekran A. Evaluation of Cassia roxburghiiseed gum as binder in tablet formulations of selected drugs. Int J Pharm Sci Nanotech. 2010; 2(4): 726-732.

20. Ayorinde, JO, Odeniyi MA, Oyeniyi YJ. Material and compression properties of native and modified plantain starches. Farmacia. 2013; 60(3): 574 - 590 .

21. Franceschini F, Selmin S, Monghetti F, Cilurzo F. Nanofiller for mechanical reinforcement of maltodextrin orodispersible films. Carbohydr Polym. 2016; 135: 676-681.

22. Odeniyi MA, Oyedokun BM, Bamiro OA. Native and microwave-modified Terminalia mantaly gums as sustained-release and bioadhesive excipients in naproxen matrix tablet formulations. Polim Med. 2017; 47(1): 35-42.

23. British Pharmacopoeia. The pharmaceutical press, Her Majesty's Stationary office: London, 2010.

24. Ghule BV, Darwhekar GD, Jain DK, Yeole PG. Evaluation of binding properties of Eulophia campestris wall mucilage. Ind J Pharm Sci. 20o6; 68 (5): 566-569.

25. Odeku OA, Itiola OA. Evaluation of the effects of khaya gum on the mechanical and release properties of paracetamol tablets. Drug Dev Ind Pharm. 2oo3; 29: 311 - 320 .

26. Adeleye OA, Femi-Oyewo MN, Odeniyi MA, Babalola CO. Compaction and mechanical properties of Cissus populnea gum. Trop J Nat Prod Res. 2018; 2(10): 447-451.

27. Rippi M, Antikainem O, Niskanen T, Yiruusi J. The effect of compression force on surface structure, crushing strength, friability and disintegration time of erythromycin acistrate tablets. Eur J Pharm Biopharm. 1998; 46(3): 339-345.

28. Adjei FK, Osei YA, Kuntworbe N, Ofori-Kwakye K. Evaluation of the disintegrant properties of native starches of five new cassava varieties in paracetamol tablet formulations. J Pharm [Internet]. 2017; Article ID 2326912, https://doi.org/10.1155/2017/2326912.

29. Hixson AW, Crowell JH. Dependence of reaction velocity upon surface and agitation. J Ind Eng and Chem. 1931; 23: 923-931.

30. Higuchi T. Rate of release of medicaments from ointment bases containing drugs in suspension. J Pharm Sci. 1961; 50: 874 - 875.

31. Adeleye AO, Odeniyi MA, Jaiyeoba KT. The influence of cissus gum on the mechanical and release properties of paracetamol tablets - a factorial analysis. J Bas Appl Pharm Sci. 2010; 31 (2): 131-136. 